\title{
ADVERSE DRUG REACTIONS: AN OVERVIEW OF THE OLD AND CONTINUOUS CHALLENGE TO DRUG THERAPY AND DEVELOPMENT
}

Abdelbaset A Elzagallaai, Department of Pediatrics, Schulich School of Medicine and Dentistry, Western University, London, Ontario, Canada. Department of Toxicology, Faculty of Pharmacy, Benghazi University, Benghazi, Libya.

Received: 6 June 2012, Accepted in revised form: 24 September 2012, Published: 26 September 2012 Corresponding author: Abdelbaset A Elzagallaai, e-mail: aelzagal@uwo.ca

\begin{abstract}
:
Adverse drug reactions (ADRs) represent a major health problem worldwide and constitute a big challenge to drug therapy and the drug development process. ADRs are responsible for $3 \%$ of total hospital admissions and occur in 10 to $20 \%$ of hospitalized patients. It has been estimated that ADRs account for at least 100,000 deaths annually in the United States alone ranking them as the fifth leading cause of death. According to the World Health Organization definition an ADR is a noxious and unintended response to a drug that occurs at a dose normally used in man for prophylaxis, diagnosis or therapy. This commonly used definition, however, excludes other drug therapy consequences such as drug abuse, accidental and inadvertent drug overdose and therapeutic failure. ADRs are classified into two main groups: Type A, which are predictable from the drugs' normal pharmacological actions and are dose dependent and Type B, which are unpredictable, unrelated to the drugs' pharmacology and do not have clear dose dependency. This is an overview of the currently used definitions and classifications of ADRs in clinical pharmacology and toxicology. Specific relevant examples are cited and some important points are discussed in the light of current knowledge. A special emphasis is made on the importance of ADRs in clinical drug therapy and drug development, which are the areas where ADRs play the most significant role.
\end{abstract}

Key words: Adverse drug reactions, side effects, adverse drug events, idiosyncratic reactions, drug hypersensitivity.

$$
\begin{aligned}
& \text { الملخص العربي: } \\
& \text { التفاعلات الدوائية الضارة: لمحة عامة عن التحدي القديم والمستمر للعلاج والتطوير الدوائي } \\
& \text { عبدالباسط عبدالنبي الزقلعي }
\end{aligned}
$$

تمثل التفاعلات (التداخلات) الدوائية الضارة مشكلة صحية كبيرة في جميع أنحاء العالم، وتنثكل تحديا كبيرا للعلاج الدوائي ولعملية التنمية

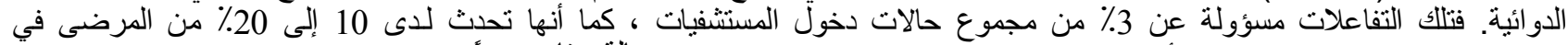

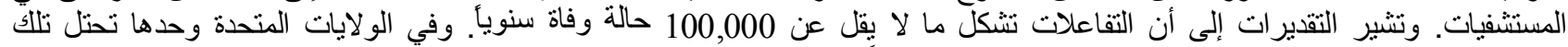

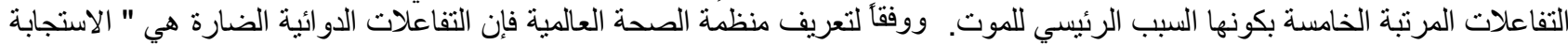

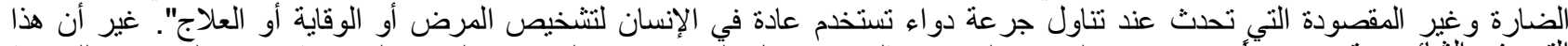

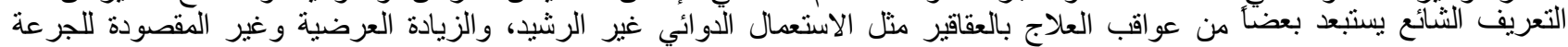

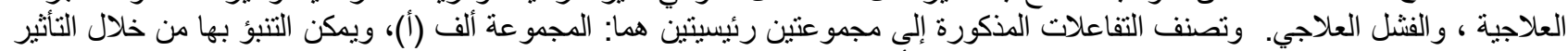

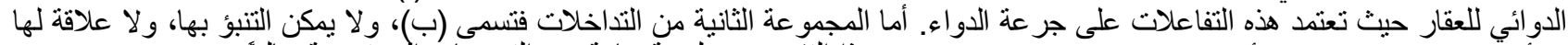

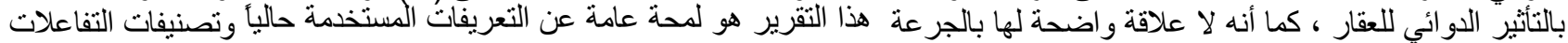

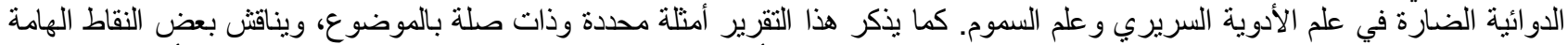

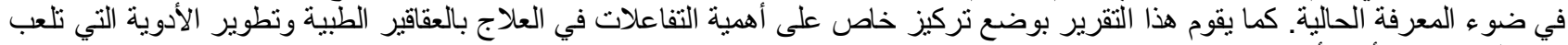
دور التفاعلات الأكثر أهمية. الكلمات الفقتاحية: التفاعلات الدوائية الضارة، والآثار الجانيية، الآثار الدوائية الضارة،التفاعلات ذانية الحساسية ، فرط الحساسية للأدوية. 


\section{INTRODUCTION:}

I

atrogenic diseases (diseases caused by Physician intervention and self medication) have always been a concern to medical practitioners. It was documented in the Code of Hammurabi, $2200 \mathrm{BC}$, that 'a physician who causes a patient's death should lose his hands'. Also, one of the most recognized principles of medicine is 'Primum non nocere' (first, do not harm) that was pleaded by Hippocrates (460-370 $\mathrm{BC}$ ) to emphasize the ethical issue of harming the patient during a medical procedure or therapy[1]. Highlighting this issue, Abubaker Al-Rhazes (860-932 AD), the great Islamic physician and scientist, advised that ' if simple remedies are effective, do not prescribe compound remedies', in reference to the increased possibility to develop adverse events when multiple remedies are used[2]. Nevertheless, the history of medicine and drug therapy is full of disasters of adverse drug events in addition to the everyday patient suffering and extra healthcare costs caused by these events. The death of more than 100 patients as a result of consumption of diethylene glycol used to prepare sulfonamide elixirs in 1937 led to the declaration of a Federal Act in the United States that prohibits marketing new drugs without demonstrating their safety [3]. The 'Thalidomide disaster' is one of the most famous drug-induced catastrophes in the history of medicine; hundreds of babies were born with severe anomalies due to in utero exposure to the drug[4]. Thalidomide was introduced as a safe and well-tolerated analgesic and was used by pregnant women to ameliorate morning sickness. The teratogenic effects of thalidomide were discovered after a sudden upsurge in the incidence of a rare congenital abnormality called Emelia (no limbs) and phocomelia (short deformed limbs) was recorded in the countries where thalidomide was marketed. In the aftermath of this disaster, many countries established agencies including The World Health Organization (WHO) to serve as a watchdog for drug safety. One of the first recorded establishments of a regulatory authority to enforce a standard code on medical products and to protect the public against fraud, trickery and charlatanry was the founding of the office of the hisba (hisba in Arabic means 'to compute' or 'to measure'; the officer was called muhtasib) by the Abbasid Caliph Abu Ja'far al-Mansur during the early ninth century in the Islamic empire [5]. The Office was equivalent to the current US Food and Drug Administration (FDA) and was in
Abdelbaset A Elzagallaai

charge of ensuring both the correct use of weight and measures and the safety of food products and medicinal preparations [6]. 'It is a duty of the muhtasib that he exact from practitioners of medicine the oath of Hippocrates, that they will not administer a harmful drug, that they will not prescribe a poison for a patient, that they will not describe poisons to the people, that they will not inform a woman of a drug which abort the embryo nor a man to avoid conception, that they will turn their eyes from the women's quarters when they enter them to visit a patient, that they will not reveal secrets and not tear away the veil, and that they will not be inquisitive in what should remain unknown'[7]. These are very impressive details on how health care providers should conduct their service, as they have long continued to deserve Voltaire's stricture that they 'poured drugs of which they know little into bodies of which they know less [8]. In modern days, adverse drug reactions (ADRs) are a welldefined type of iatrogenic disease. According to the WHO definition, which has been in use for more than forty years, an ADR is a noxious and unintended response to a drug that occurs at a dose normally used in man for prophylaxis, diagnosis or therapy [9]. However, this definition is too strict and does not include all adverse drug effects [10]. The word 'noxious' used in this definition, which means harmful or hurtful, may cause minor ADRs to be overlooked during ADR monitoring. The WHO definition also excludes events such as medication errors, drug abuse, accidental and intentional overdose and therapeutic failure. Therefore, another term, adverse drug events (ADE), was introduced to cover all these effects. The term 'ADE' is broader and is defined as any undesirable effect associated with drug use. It does not limit the definition to unintended and undesirable responses to the drug at normal doses but also includes all of the aforementioned effects that are not included by the WHO definition of ADRs. Furthermore, the definition of ADEs implies some ambiguity about the attribution of the event in terms of the drug being the cause, which might be clinically more relevant since it is not always possible to establish causality. Other authors have also suggested a more comprehensive definition of an ADR such as 'an appreciably harmful or unpleasant reaction, resulting from an intervention related to the use of a medicinal product, which predicts hazard from future 
administration and warrants prevention or specific treatment, or alteration of the dosage regimen, or withdrawal of the product' [11]. Other terms that are used to refer to adverse effects of drugs are side effects, toxic effects and undesirable effects and these terms have different definitions from ADRs. Side effects, for instance, include all drug effects other than the ones that are intended for its use, although they are not always undesirable. For instance, sedation caused by antihistamines to treat the common cold is a side effect but it may promote needed bed rest for the patient. Toxic effects are reserved for adverse effects at supra-therapeutic doses of drugs (toxic doses); however, technically there is no difference between pharmacological and toxicological effects as both may have the same underlying mechanism. Adverse drug reactions are a major health problem and cause high rates of morbidity and mortality. It has been estimated that ADRs are responsible for more than 100,000 deaths annually in the United States, ranking them
Abdelbaset A Elzagallaai

between the fourth and sixth leading causes of death, after heart disease, cancer, stroke, pulmonary disease and accident [12]. ADRs are responsible for at least $3 \%$ of hospital admissions, complicate $5 \%$ of therapeutic courses and occur in 10 to $20 \%$ of hospitalized patients, although accurate estimation of such cases is difficult due to lack of reporting [13]. ADRs also represent a heavy economic burden on the health care system manifested in extra admissions and extended hospitalization [14].One of the most commonly used classifications of ADRs is the one suggested by Rawlins and Thompson nearly 4 decades ago [15]. According to this classification, ADRs are divided into two main groups. Type A reactions, which are usually predictable, dose-dependent and related to the pharmacological action of the drug, and type-B reactions, which are unpredictable, have delayed onset, are typically unrelated to the drug pharmacology and do not have clear dose-dependency, Table land Figure 1. [15].

Table1. Comparison between Type A ADRs and Type B ADRs.

$\mathrm{ADRs}=$ Adverse drug reactions.

\begin{tabular}{|c|c|c|}
\hline Feature & Type A ADRs & Type B ADRs \\
\hline Frequency & $\sim 75 \%$ of all ADRs & $\sim 25 \%$ of all ADRs \\
\hline Predictability & Predictable & Unpredictable \\
\hline $\begin{array}{l}\text { Relatedness to the drug } \\
\text { pharmacology }\end{array}$ & Related & Unrelated \\
\hline Severity & Generally mild & Severe and can be life threatening \\
\hline Dose dependency & Dose dependent & $\begin{array}{l}\text { Do not have clear dose dependency; however, generally } \\
\text { occur at large mass doses }\end{array}$ \\
\hline Response to dose reduction & Generally respond & $\begin{array}{l}\text { Generally occur at all doses. However, desensitization } \\
\text { using gradually increasing dosage has been used. }\end{array}$ \\
\hline
\end{tabular}




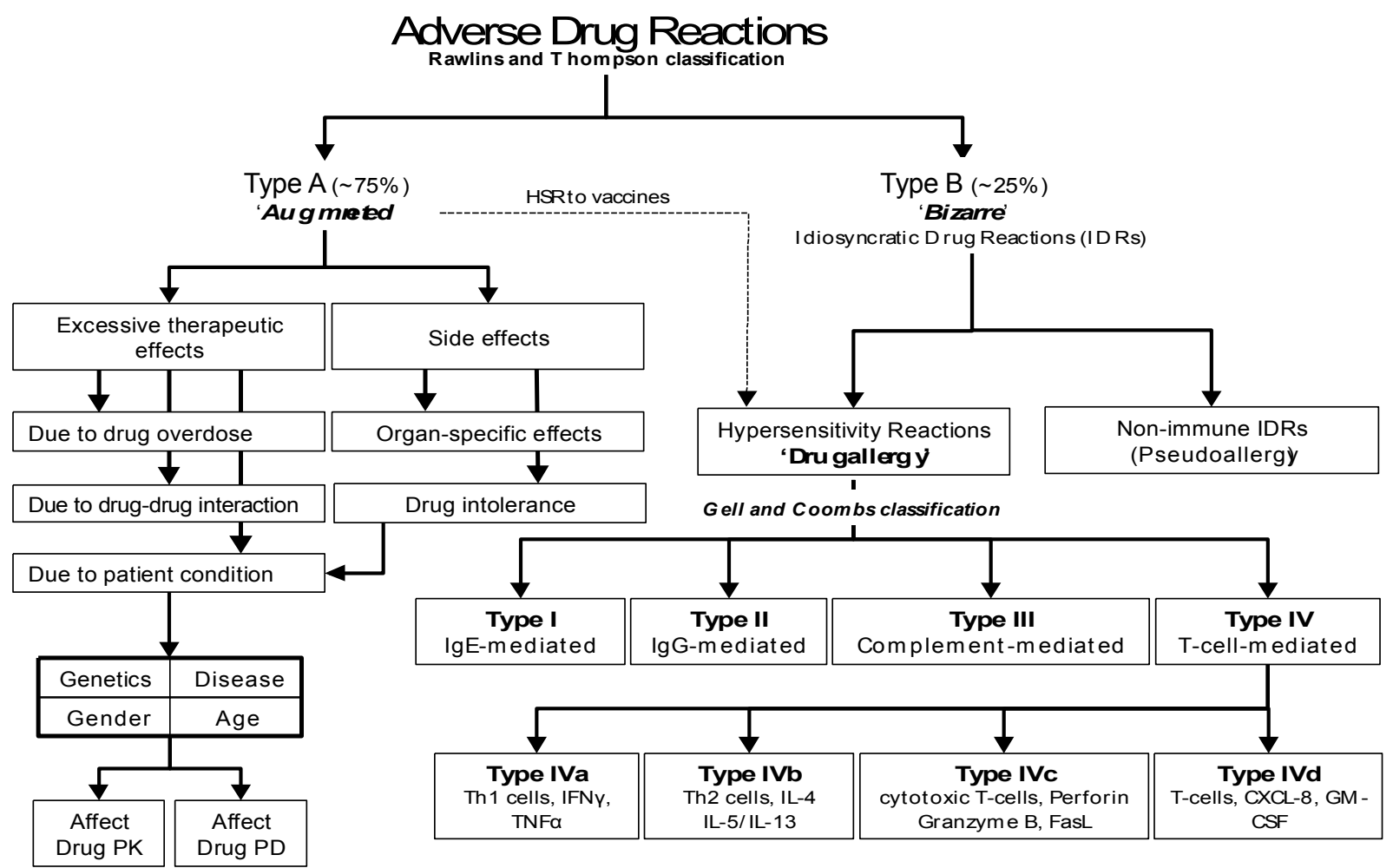

Figure1. Classification of ADRs (see text for details).

TYPE A ADVERSE DRUG REACTIONS:

Although exaggerated and can be harmful, these reactions are typically expected from the normal drug pharmacology. Bradycardia due to antihypertensive therapy with the $\beta 1$ receptor antagonist atenolol and warfarin-induced hemorrhage are examples of this type of ADR. These types of reactions are more common than type B reactions. They represent around $75 \%$ of the total incidence of ADRs; however, they tend to be milder and respond to dose reduction. They can manifest as excessive therapeutic effects such as in the aforementioned examples or as side effects that may or may not be mediated by the same mechanism of action. In general, excessive therapeutic effects can be produced as a result of drug overdose. The WHO definition of ADRs does not include effects due to drug overdose, which is considered a medication error; however, drug overdose can also occur at normal therapeutic doses as a result of increased patient susceptibility. Strictly speaking, this is what is meant 'linguistically' by the term 'drug hypersensitivity' although this term has been strongly linked to immune-mediated reactions. These effects will be discussed in greater detail in a later section in this review. Drug-drug and sometimes drug-food interactions can cause ADRs to occur as a result of modulation of the drug pharmacokinetics and/or pharmacodynamics. Absorption, distribution, metabolism and excretion (ADME) of a drug can be affected by the concurrent administration of another drug or food. Many effects can be exerted by drugs that alter gastric and intestinal absorption of another drug. These effects include, but are not limited to, chemical chelation, changes in gastric $\mathrm{pH}$ or motility and interference or enhancement of the function of Transport proteins. These factors can Affect both the rate and extent of the absorption of these drugs. Co-administration of drugs can also alter drug distribution by competing for plasma or tissue binding sites. Also, induction or inhibition of phase I and II metabolizing enzymes can largely modulate drug metabolism and, hence, its pharmacology. The most common example is the stimulation or inhibition of the liver microsomal phase I cytochrome P450 isozymes. Many drugs such as barbiturates,carbamazepine, phenytoin, rifampin and glutethimide can induce CYP 450 enzymes and promote the metabolism of other drugs. Amitriptyline, imipramine, chlorpromazine, 
haloperidol, clozapine and grapefruit juice inhibit some CYP 450 isozymes activities and can reduce drug metabolism. The final results of drug interference with drug metabolism are determined by the nature of the drug pharmacology depending on whether the parent drug or the metabolite(s) are more active. Renal excretion of some drugs can be affected by cotherapy either by changing urinary $\mathrm{pH}$ or interfering with active transport systems. Drugs can also act synergistically and produce toxic effects or alternatively counteract the effects of each other and result in therapeutic failure. These effects are not necessarily mediated through binding to the same receptors. An example of the toxic effect of synergism is the gastric bleeding that can result from concomitant administration of non-steroidal anti-inflammatories (NSAIDs) and anticoagulant therapy [16]. Patient conditions including genetic composition, disease state, age and gender is a major risk factor for ADRs $[17,18]$. Genetics controls drug pharmacokinetics and pharmacodynamics that can result in alteration in drug bioavailability, plasma levels and the intensity of drug response ,Figure 1.Type A ADRs may manifest as side effects that may or may not be related to the primary therapeutic effect or mediated by the same mechanism. Examples of drug side effects are $\mathrm{H} 2$ antagonistsinduced sedation, the anti-muscarinic effects of tricyclic antidepressants and gastric bleeding due to the use of NSAIDs. Although the mechanisms responsible for many of these effects are different from the mechanisms of the drugs' primary therapeutic effects, they are still expected from the drugs' pharmacology. These side effects can be organ- Specific or generalized In nature. Drug intolerance or drug sensitivity (not to be confused with immune-mediated drug hypersensitivity or drug allergy) occurs when the patient has a low threshold to the normal pharmacological action of the drug or its side effects. Drug intolerance can also emerge due to drug overdose, drug-drug interaction or patient conditions that include genetics, disease state, gender or age. These patient conditions are considered risk factors for both Type A and Type B ADRs.

1) Genetic composition plays a major role in determining patient susceptibility to develop an ADR. Polymorphisms in the expression of some metabolic enzymes especially of the CYP 450 family have been linked to ADRs susceptibility. 2) Renal and liver diseases can alter and/or pharmacodynamics of the drug and result in development of ADRs.
3) The female gender is a risk factor for ADRs, which may be due to the difference in hormonal milieu.

4) Extremes of age (i.e., very young and very old) are risk factors for ADRs, which is probably due to change in drug metabolism.

\section{TYPE B ADVERSE DRUG REACTIONS:}

Type B ADRs constitutes about $25 \%$ of total ADRs and are characterized by being unpredictable, unrelated to the normal drug pharmacology and having no clear dosedependency. They are also called idiosyncratic drug reaction (IDRs). The word 'idiosyncrasy' originates from the Greek words 'idios', meaning one's own, 'syn', meaning with and, 'krasis', meaning mixture, peculiar or odd habit. In pharmacology 'idiosyncratic' refers to an effect that is unpredictable and cannot be explained by the drug pharmacology and the term is broadly synonymous to type B ADRs. Idiosyncratic (Type B) reactions can either be immune-mediated in nature, called hypersensitivity reactions (drug allergy), or if the immune mediation cannot be demonstrated are referred to as 'non-immune IDRs' or pseudoallergies. Although the term 'hypersensitivity' does not necessarily imply any immune system involvement, the term 'allergy' does, it is widely accepted that drug hypersensitivity reactions are largely caused by immune reactions [19]. Immune-mediated Type B ADRs (drug hypersensitivity reactions, DHRs) represent approximately one-sixth of all ADRs; however, their precise incidence is not known due to underreporting [20]. Diagnosis of this type of $\mathrm{ADR}$ is challenging due to their vague clinical presentation, resemblance to other conditions and the poor temporal relationship between drug intake and appearance of the reaction [21, 22]. Combs and Gells divided allergic reactions into four categories designated by Roman numbers: Type I, which is mediated through immunoglobulin E (IgE); Type II, mediated by IgG and IgM; Type III, mediated by formation of an immune complement complex; and Type IV, which is T-cell mediated. Further Understanding of the heterogeneity of T-cell Clones' involvement in DHRs has lead to further Dividing of Type IV hypersensitivity reactions into four subtypes: Type IVa, which involve Th1 T-cells that express Interferon $\gamma$ (IFN $\gamma$ ) and tumor necrosis factor $\alpha(\mathrm{TNF} \alpha)$, Type IVb, Which involve Th2 T-cells that express the 
interleukins IL4, IL5 and IL13, Type IVc, which are mediated through CD8+ cytotoxic T-cells that work as effector cells though the perforin/granzyme B, granulisin and FasL pathways and Type IVd, which are mediated through activation of neutrophils by T-cells that secrete the chemokines CXCL- 8 and GM-CSF ,table 2. [23].

Table2. Classification of immune-mediated hypersensitivity reactions.

\begin{tabular}{|c|c|c|c|c|}
\hline Type & Mediator & Pathogenesis & Clinical picture & Chronology \\
\hline I & $\operatorname{IgE}$ & $\begin{array}{l}\text { Degranulation of Mast cells } \\
\text { and basophils }\end{array}$ & $\begin{array}{l}\text { Urticaria; Anaphylaxis; Allergic } \\
\text { rhinitis;Bronchospasm; Angiooedema; }\end{array}$ & $\begin{array}{l}\text { Immediate } \\
(\leq 1 \mathrm{hr})\end{array}$ \\
\hline II & $\mathrm{IgG} / \mathrm{M}$ & FcR dependent cell lysis & Blood Cell Dyscasia & $\begin{array}{c}\text { Intermediate } \\
\text { (5-14 days) }\end{array}$ \\
\hline III & $\mathrm{IgG} / \mathrm{M}$ & $\begin{array}{l}\text { FcR-dependent immune } \\
\text { complexes deposition }\end{array}$ & $\begin{array}{c}\text { Serum Sickness; Vasculitis } \\
\text { Arthus reaction }\end{array}$ & $\begin{array}{l}\text { Intermediate } \\
\text { (7-8 days) }\end{array}$ \\
\hline $\mathrm{IVa}$ & TH1 (IFN $\gamma$, TNF $\alpha)$ & $\begin{array}{l}\text { Monocyte/macrophage } \\
\text { mediated inflammatory } \\
\text { response }\end{array}$ & Eczema & $\begin{array}{l}\text { Delayed } \\
(1-3 \text { weeks })\end{array}$ \\
\hline $\mathrm{IVb}$ & $\begin{array}{l}\text { TH2-IL4, IL5, } \\
\text { IL13) }\end{array}$ & $\begin{array}{l}\text { Eosinophils mediated } \\
\text { inflammatory response }\end{array}$ & $\begin{array}{l}\text { Maculopapular exanthema } \\
\text { Bullous exanthema }\end{array}$ & $\begin{array}{c}\text { Delayed } \\
(2-7 \text { weeks })\end{array}$ \\
\hline IVc & $\begin{array}{l}\text { Cytotoxic T cells } \\
\text { (Perforine, } \\
\text { Granzym B, FasL) }\end{array}$ & Cytotoxicity/Apoptosis & $\begin{array}{l}\text { Maculopapular exanthema } \\
\text { Bullous/pustular exanthema }\end{array}$ & $\begin{array}{c}\text { Delayed } \\
(1-3 \text { weeks })\end{array}$ \\
\hline IVd & $\begin{array}{c}\text { T cells (IL8, } \\
\text { CXCL8, GM-CSF) }\end{array}$ & $\begin{array}{l}\text { Neutrophils mediated } \\
\text { inflammatory response }\end{array}$ & $\begin{array}{c}\text { AGEP } \\
\text { Behset's disease }\end{array}$ & $\begin{array}{l}\text { Intermediate } \\
\text { ( } \leq 2 \text { days })\end{array}$ \\
\hline
\end{tabular}

The different types of the immune-mediated drug hypersensitivity reactions usually manifest in distinct clinical presentations. Type I reactions include urticaria, angioedema, allergic rhinitis, asthma and systemic anaphylaxis through activation of mast cells. Among the drugs commonly involved in such reactions are the $\beta$ lactam antibiotics. Commonly observed clinical manifestations of Type II reactions, which are caused by the formation of drug-specific antibodies that interact with $\mathrm{Fc}$ receptors $(\mathrm{FcR})$ on the surface of certain cells such as macrophages, natural killer (NK) cells, granulocytes and platelets include hemolytic anemia, thrombocytopenia and blood cell dyscraias. Drugs involved in the Type II reactions include penicillins, cephalosporins, levodopa, methyldopa, quinidine and heparin. Type III reactions are rare and commonly manifest as serum sickness-like reaction and vasculitis. Drugs involved include cefaclor, trimethoprim-sulfamethoxazole, cephalexin,

Amoxicillin, NSAIDs and diuritics as well as biologicals such as rituximab, infliximan and natalizumab. The four subtypes of Type IV reaction also differ in their clinical manifestations. Type IVa reactions such as contact dermatitis result from activation of monocytes/macrophages by Th1 T-cells secreting large amounts of IFN $\gamma$ and TNF $\alpha$. In contrast Type IVb corresponds to the Th2-type immune response through T-cells expressing the cytokines IL-4, IL-13 and IL-5 that activate eosinophils and results in maculopapular exanthemas with eosinophilia. Type IVc reactions manifest clinically as maculopapular and bullous exanthemas. Finally, an example of Type IVd reactions is the acute generalized exanthematouspostulesis (AGEP) [24]. The molecular mechanism(s) underlying hypersensitivity reactions is not fully understood although thought to be immune-mediated[21, 25]. Generation of reactive nucleophiles that are able to covalently modify endogenous

macromolecules (proteins and DNA) through metabolism is the first step in the cascade of events leading to activation of the immune system and eliciting a hypersensitivity reaction (HSR) [15, 26-28]. This is called the 'reactive metabolite hypothesis' and was introduced by Stephen Spielberg and Neil Shear during the early 1980s (Figure 2) [29-31]. Reactive metabolites serve in two ways in the suggested pathophysiological pathway of HSRs. First, they can haptenate endogenous macromolecules, providing an antigen that is recognized by the immune system as a non-self (the hapten hypothesis) [32, 33] and presented by antigen presenting cells (APCs) to T-lymphocytes in the context of the Major Histocompatibility complex (MHC), Figure2. Second, reactive metabolites

can induce tissue necrosis and apoptosis, which release 'danger signals' that prime antigen presetting cells and other immune cells for the reaction (the danger hypothesis) [34]. Reactive 
metabolites and parent drugs can also interact directly and non-covalently with T-lymphocytes leading to their activation according to the " $\mathrm{p}-\mathrm{i}$ hypothesis' (pharmacological interaction of drugs with the immune cells) [35]. Other ADRs that are classified as Type B ADRs and are considered non-immunological include those that are caused by genetic deficiency in specific enzymes. An example of this occurs in individuals whose erythrocytes are deficient in glucose-6-phosphate dehydrogenase (G6PD). Haemolysis may occur in those individuals if they are exposed to drugs such as aspirin, sulfonamides, some antimalarials and antileprotics[36]. Also, people with hepatic porphyria have abnormal heme biosynthesis and drugs such as oral contraceptives, barbiturates and sulfonamides can precipitate the symptoms. Another example is malignant hyperthermia that occurs in 1 in 20,000 patients exposed to Inherited in an autosomal dominant fashion. Also, ototoxicity due to aminoglycoside antibiotics, Halothane and methoxyflurane in combination with succinylcholine during anesthesia and is such as gentamicin, occurs in 1 in 10,000 patients exposed to the drug and is thought to be genetically determined. One unpredictable ADR In particular, that is notable for being a major cause of drug withdrawal from the market is the long QT syndrome. This condition develops as a delay between the QRS complex and T wave in the electrocardiogram (ECG) and can progress to the life-threatening ventricular arrhythmias torsades de pointes and ventricular fibrillation [37]. Other classes of ADRs have been suggested including Type $\mathrm{C}$ (chronic), Type D (delayed), Type E (withdrawal, end of use) and Type F (therapeutic failure).

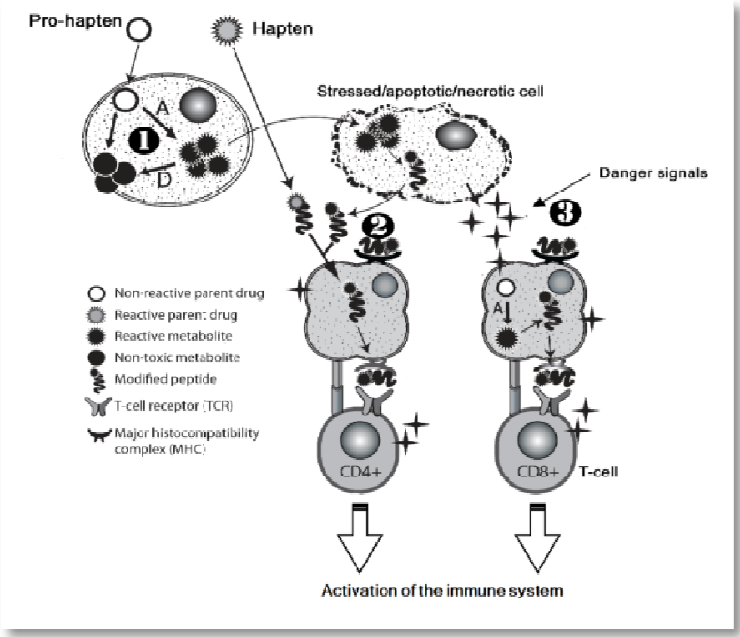

Figure2. Mechanisms of immune-mediated hypersensitivity reactions. (1) The reactive metabolite hypothesis. (2) The hapten hypothesis. (3) The danger hypothesis (see text for details).

\section{ADVERSE DRUG REACTIONS AS A CLINICAL PROBLEM:}

The Scottish philosopher David Hume (17111776) has said that 'it is impossible to separate the chance of good from the risk of ill', a statement that is still applicable to modern drug therapy. Adverse drug reactions are an inseparable part of the medical practice and to enjoy the benefits of drug therapy, one should accept the risk of ADRs. It is the delicate balance between risk and benefits that gives the ethical cover to prescribe and dispense drugs to patients, which may severely harm or even kill them. Lazarou and colleagues (1998) estimated through meta-analysis that ADRs kill around 100,000 patients in North America every year.

Similar international data is not available; however, one may extrapolate staggering numbers from the North American study. Furthermore, these numbers represent only serious ADRs that lead to death, and do not take into account 'less serious' ADRs that can cause severe and disabling injuries. In addition, it has been estimated that only 5\% of ADRs are reported [14]. Adverse drug reactions, especially those of idiosyncratic nature, are very difficult to diagnose and the causality relationship between drug administration and the ADR is not always Possible to establish [22, 38]. Underreporting of ADRs is a major problem since lack of data limits our understanding of the real size of the Problem. Type B ADRs are more problematic for clinical practice because of their unpredictability 
and undefined clinical picture. These types of reactions are often confused with other conditions such as bacterial and viral infections. Ironically, drugs that are mostly associated with HSRs are those that are used to fight infections (antibacterial and antivirals). This places the treating physician in a great dilemma as to whether to stop or continue the drug. Clinical experience and diagnostic aids (in vivo and in vitro test) are of great value in helping the doctor to make the correct decision; however, those are not always available except in advance wellequipped centers in developed countries. This leaves patients in remote areas in less developed societies very vulnerable to severe and sometimes life-threatening ADRs.Because of the rare nature of these reactions, many doctors and nurses are not exposed to them during training in medical and nursing Schools and thus lack any experience in dealing with such cases Therefore Much effort should be made to train health care providers in these areas to recognize and treat rare and dangerous ADRs. Over $50 \%$ of ADRs are possibly or definitely preventable [39] and a large part of these ADRs are caused by medication errors (MEs) that can be prevented by following a better medical practice. Fortunately, many MEs do not result in any ADEs or go unnoticed by both the patient and the doctor ,Figure 3. However, MEs that result in detected ADEs or ADRs can be very embarrassing for the health care system and especially for the prescribing doctor and pharmacist. It has been estimated that 98,000 fatalities result from MEs annually in the US and that approximately $26 \%$ of preventable ADEs caused by MEs cost around $\$ 3.5$ billion annually [40, 41].

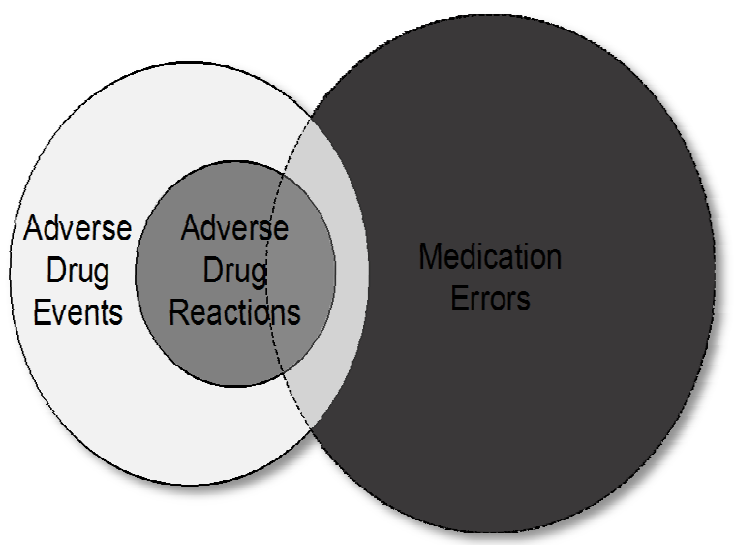

Figure3. A Venn diagram showing the interaction and overlapping among adverse drug reactions, adverse drug events and medication errors. Size of the each circle represents the relative incidence of each effect.

\section{ADVERSE DRUG REACTIONS AND DRUG DEVELOPMENT:}

Drug development is a complex, high risk and costly process. Before drugs are approved for use in humans, compounds and elements with potential therapeutic application undergo a series of stages starting with in vitro testing that includes identifying the leading compound and biological target. Preclinical testing in rodents and non-rodent laboratory animals as well as basic genotoxicity and pharmacokinetics determinations are important to demonstrate safety of the drug. Preclinical testing is also a legal and ethical prerequisite before starting clinical trials of the drug. Clinical trials take place in 4 stages: Stage I, using 30-50 mainly Young healthy male volunteers to determine tolerance, safe dosage range and basic kinetics and metabolism; stage II, on limited number of patients (250-300) under close monitoring to determine preliminary efficacy and short term safety. Stage III, using extended number of patients (300-3000) to obtain definitive evidence of efficacy and safety and identify adverse events. At this point the drug developer can apply for the authority approval for marketing. Stage IV is the postmarketing surveillance for less common adverse events and drug interactions. The total time required to complete the entire process is 12 to 20 years including the post-marketing surveillance. Emergence of serious ADRs during drug development process can lead to either aborting the development process in early stages or withdrawal of the drug from markets at late stages [42]. Some rare ADRs can only be detected after the post-marketing stage when the drug is used in large number of patients. This accounts for the largest economic loss for drug companies due to the high cost of development and litigation [43]. For comprehensive review of safety withdrawal of drugs from international markets please refer to the review by Fung et al., (2001) [44]. Common and predictable ADRs (i.e., Type A) are usually detected during premarketing testing and dealt with by reducing the dose or avoiding usage in certain conditions of drug combinations. Rare reactions (mostly type B), however, require the exposure of larger populations before they can be recognized and these constitute a great challenge to the drug development process. In 1999, the cyclooxygenase selective inhibitor rofecoxib (Vioxx ${ }^{\circledR}$ ) was developed by Merck \& Co., Inc. and approved by the FDA for osteoarthritis and other conditions as an anti-inflammatory with no GIT side effects. However, in 2004, a post-marketing clinical trial connected the use of Vioxx to a 
high incidence of cardiovascular complications, which led to withdrawal of the drug from market. Another drug that was withdrawn from market was the non-sedating antihistamine terfenadine (Seldane ${ }^{\circledR}$ ), which was found to increase the risk of developing a dangerous and life threatening ADR called long QT syndrome. These ADRs rarely occur and could not be identified in the premarketing stages of drug development.

\section{CONCLUSION:}

Adverse drug reactions are unavoidable consequences of modern drug therapy; however, better understanding of their epidemiology and pathophysiology can help reduce their negative impact of unnecessary patient suffering and costly financial burden. Health care providers should be properly trained to recognize, prevent and treat ADRs. This task is not always easy without full collaboration between different areas and disciplines of patient care and implementation of a prompt and vigorous system within the hospital settings to facilitate this collaboration. Lack of reporting of ADRs masks the true magnitude of the ADR problem. Government authorities and regulatory agencies should put more pressure on the pharmaceutical companies and health care facilities (including pharmacies and doctors' clinics) to actively engage in the reporting process.

\section{FUNDING:}

No funding source was used in the preparation of this manuscript.

\section{ACKNOWLEDGMENTS:}

I would like to thank Ms. Lindsey Chow for editing the manuscript.

\section{REFERENCES:}

1) Davies DM. History, in Textbook of adverse drug reactions, D.M. Davies, Editor 1991, Oxford University Press: Oxford. p. 1-4.

2) Levey M. Mediaeval Arabic physicians: their education and practice. Connecticut medicine. 1963; 27: 137-138.

3) Geiling E and Cannon P. Pathogenic effects of elixir of sulfonamide (diethylene glycol) poisoning. . JAMA. 1938; iii: p. 919.

4) Speirs AL. Thalidomide and congenital abnormalities. Lancet. 1962; 1(7224): 303-305.

Levey M. Fourteenth century Muslim medicine and the Hisba. Medical history. 1963; 7: 176182.
5) IbnKaldun AZ. Muqaddima (middle of seventh century H). 1329; Cairo. p. 247-248.

6) Khan M. The role of islamic state in consumer protection. Pakistan J Islamic Research. 2011; 8: 31-44.

7) Davies D. History, in Textbook of adverse rug reactions, M. Davies, Editor 1991, Oxford University Press: Oxford, UK. p. 1-4.

8) $\mathrm{WHO}$, International drug monitoring: the role of national centres. World Health Organ. Tech Rep Ser 1972; 498: 1-25.

9) Bates DW. et al. Incidence of adverse drug events and potential adverse drug events. Implications for prevention. ADE Prevention Study Group. JAMA. 1995; 274(1): 29-34.

10) Edwards IR. and Aronson JK. Adverse drug reactions: definitions, diagnosis, and management. Lancet. 2000; 356(9237): 1255-1259.

11) Lazarou J, Pomeranz BH and Corey PN. Incidence of adverse drug reactions in hospitalized patients: a meta-analysis of prospective studies. JAMA. 1998; 279(15): 1200-1205.

12) Kvasz $M$ et al. Adverse drug reactions in hospitalized patients: A critique of a metaanalysis. MedGenMed. 2000; 2(2): E3.

13) Gruchalla RS. Clinical assessment of druginduced disease. Lancet. 2000; 356(9240): 15051511.

14) Rawlins $M$ and Thompson J. Pathogenesis of adverse drug reactions, in Textbook of adverse drug reactions, D. Davies, Editor 1977, Oxford University Press: Oxford. p. 10.

15) Sostres C and Lanas A. Gastrointestinal effects of aspirin. Nat Rev Gastroenterol Hepatol. 2011; 8(7): 385-394.

16) Park, BK and Pirmohamed $M$. Toxicogenetics in drug development. Toxicology letters. 2001; 120(1-3): 281-291.

17) Pirmohamed, $M$ et al. Adverse drug reactions. BMJ. 1998; 316(7140): 1295-1298.

18) Johansson $S G$ et al. A revised nomenclature for allergy. An EAACI position statement from the EAACI nomenclature task force. Allergy. 2001; 56(9): 813-824.

19) Demoly $P$ et al. Epidemiology and Causes of Drug Hypersensitivity, in Drug Hypersensitivity, W. Pichler, Editor 2007, Karger: Basel. p. 2-17.

20) Rieder MJ. Immune mediation of hypersensitivity adverse drug reactions: implications for therapy. Expert Opin Drug Saf. 2009; 8(3): 331-343.

21) Elzagallaai AA, Knowles SR, Rieder MJ, Bend JR, Shear NH, Koren G. Patch testing for the diagnosis of anticonvulsant hypersensitivity 
syndrome: a systematic review. Drug Saf. 2009; 32(5): 391-408.

22) Pichler WJ, Adam J, Daubner B, Gentinetta T, Keller M, Yerly D. Drug hypersensitivity reactions: pathomechanism and clinical symptoms. Med Clin North Am. 2010; 94(4): 645-664, xv.

23) Hebert AA and Ralston JP. Cutaneous reactions to anticonvulsant medications. J Clin Psychiatry. 2001; 62 Suppl 14:22-26.

24) Elzagallaai AA, Garcia-Bournissen F, Finkelstein Y, Bend JR, Rieder MJ, Koren G. Severe bullous hypersensitivity reactions after exposure to carbamazepine in a Han-Chinese child with a positive HLA-B*1502 and negative in vitro toxicity assays: evidence for different pathophysiological mechanisms. J Popul Ther Clin Pharmacol. Epub 2011; 18(1): 1-9.

25) Pirmohamed $M$, Kitteringham NR and Park BN. The role of active metabolites in drug toxicity. Drug Saf. 1994; 11(2): 114-144.

26) Park BK, Kitteringham NR, Maggs JL, Pirmohamed M, Williams DP. The role of metabolic activation in drug-induced hepatotoxicity. Annu Rev Pharmacol Toxicol. 2005; 45: 177-202.

27) Knowles SR, Uetrecht J and Shear NH. Idiosyncratic drug reactions: the reactive metabolite syndromes. Lancet. 2000; 356(9241): 1587-1591.

28) Rieder MJ, Uetrecht J, Shear NH, Spielberg SP. Synthesis and in vitro toxicity of hydroxylamine metabolites of sulfonamides. J Pharmacol Exp Ther. 1988; 244(2):724-728.

29) Shear $\mathrm{NH}$ and Spielberg SB. In vitro evaluation of a toxic metabolite of sulfadiazine.

Can J Physiol Pharmacol. 1985; 63(11):13701372.

30) Shear NH and Spielberg SB. Anticonvulsant hypersensitivity syndrome. In vitro assessment of risk. J Clin Invest. 1988; 82(6):1826-1832.

31) Landsteiner K. and Jacobs J. Studies on the Sensitization of Animals with Simple Chemical Compounds. J Exp Med. 1935; 61(5): 643-656.

32) Ju C, Uetrecht JP. Mechanism of idiosyncratic drug reactions: reactive metabolite formation, protein binding and the regulation of the immune system. Curr Drug Metab. 2002; 3(4): 367-377.

33) Matzinger $P$. Tolerance, danger, and the extended family. Annu Rev Immunol. 1994; 12: 991-1045.
34) Pichler WJ. Pharmacological interaction of drugs with antigen-specific immune receptors: the $\mathrm{p}-\mathrm{i}$ concept. Curr Opin Allergy Clin Immunol. 2002; 2(4):301-305.

35) Cappellini MD. and Fiorelli G. Glucose-6phosphate dehydrogenase deficiency. Lancet. 2008; 371(9606): 64-74.

36) Routledge P. Adverse drug reactions and interactions: mechanisms, risk factors, detection, management and prevention., in Stephens' Detection of New Adverse Drug Reactions., J. Talbot and P. Waller, Editors. 2004, John Wiley \& Sons: Chichester, WS, UK. p. 91-125.

37) Elzagallaai AA, Knowles SR, Rieder MJ, Bend JR, Shear NH, Koren G. In vitro Tests for the Diagnosis of Anticonvulsant Hypersensitivity Syndrome (AHS): A Systematic Review. Mol Diagn Ther. 2009; 13(5): 313-330.

38) Davies EC, Green CF, Taylor S, Williamson PR, Mottram DR, Pirmohamed M. Adverse drug reactions in hospital in-patients: a prospective analysis of 3695 patient-episodes. PLoS ONE. 2009; 4(2): e4439.

39) Pham JC, Aswani MS, Rosen M, Lee H, Huddle M, Weeks K, Pronovost PJ. Reducing medical errors and adverse events. Annu Rev Med. 2012; 63: 447-463.

40) Weingart $S N$, McL Wilson R, Gibberd RW, Harrison B. Epidemiology of medical error. West J med. 2000; 172(6): 390-393.

41) Lasser KE, Allen $\mathrm{PD}$, Woolhandler SJ, Himmelstein DU, Wolfe SM, Bor DH. Timing of new black box warnings and withdrawals for prescription medications. JAMA. 2002; 287(17): 2215-2220.

42) Issa AM, Phillips KA, Van Bebber $S$, Nidamarthy HG, Lasser KE, Haas JS, Alldredge BK, Wachter RM, Bates DW. Drug withdrawals in the United States: a systematic review of the evidence and analysis of trends. Curr Drug Saf. 2007; 2(3): 177-185.

43) Fung M, Thornton A, Mybeck K, HsiaoHui J, Hornbuckle K, Muniz E. Evaluation of the characteristics of safety withdrawal of prescription drugs from worldwide pharmaceutical markets 1960 to 1999. Drug Inf J. 2001; 35: 293-317 